\title{
Analisis in Silico Senyawa Fitokimia dari Fraksi $n$-Heksana Daun Semanggi (Marsilea crenata Presl.) sebagai Agen Neuroprotektif
}

\author{
Burhan Ma'arif ${ }^{1}{ }^{*}$, Ricky Arie Jatmiko ${ }^{1}$, Dewi Sinta Megawati ${ }^{1}$, Rahmi Annisa ${ }^{1}$, Hajar Sugihantoro ${ }^{1}$, \\ M. Artabah Muchlisin ${ }^{2}$, Hening Laswati ${ }^{3}$, Mangestuti Agil $^{4}$ \\ ${ }^{1}$ Jurusan Farmasi, Fakultas Kedokteran dan Ilmu Kesehatan, Universitas Islam Negeri Maulana Malik Ibrahim Malang, Malang, Indonesia \\ ${ }^{2}$ Jurusan Farmasi, Fakultas Ilmu Kesehatan, Universitas Muhammadiyah Malang, Malang, Indonesia \\ ${ }^{3}$ Departemen Kedokteran Fisik dan Rehabilitasi, Fakultas Kedokteran, Universitas Airlangga, Surabaya, Indonesia \\ ${ }^{4}$ Departemen Farmakognosi dan Fitokimia, Fakultas Farmasi, Universitas Airlangga, Surabaya, Indonesia \\ *E-mail: burhan.maarif@farmasi.uin-malang.ac.id
}

\begin{abstract}
Estrogen deficiency causes various health problems in postmenopausal women, including neurodegenerative disease. Phytoestrogens emerged as a group of compounds that can replace the estrogen function in the body, and prevent the neurodegenerative disease to occur. Semanggi (Marsilea crenata Presl.) is a typical plant in Surabaya, Indonesia, that contain phytoestrogens. The aim of this research was to determine the metabolite profile of n-hexane fraction of Semanggi leaves using UPLC-QToF-MS/MS, and then to predict the neuroprotective activity of compounds with in silico study using PyRX 0.8 software. The 100 ppm of n-hexane fraction of Semanggi leaves in DCM and methanol were injected $5 \mu$ l each into the UPLCQToF-MS/MS, and then analyzed by Masslynx 4.1 software to determine the compounds. The compounds from metabolite profiling then prepared with SwissADME webtool and Avogadro 1.90.0 software, molecular docking was done using Autodock Vina and Biovia Discovery Studio Visualizer 2016 to 3 OLS protein. Metabolite profiling process shows a total of 34 predictable compounds and 28 unknown compounds. From in silico study, it shows a total of 7 compounds that are predicted to have activities similar to estrogen. This result indicate that n-hexane fraction of Semanggi leaves has potential as a neuroprotective agent for treatment for postmenopausal women who experience estrogen deficiency.
\end{abstract}

Keywords: Marsilea crenata Presl., phytoestrogens, metabolite profiling, in silico, neuroprotective

\section{ABSTRAK}

Defisiensi estrogen menyebabkan berbagai masalah kesehatan pada perempuan pascamenopause, salah satunya adalah neurodegeneratif. Fitoestrogen merupakan golongan senyawa yang dapat menggantikan fungsi estrogen dalam tubuh dan mencegah terjadinya neurodegeneratif. Semanggi (Marsilea crenata Presl.) yang termasuk sebagai tanaman khas di Surabaya, Indonesia, diketahui mengandung fitoestrogen. Penelitian ini bertujuan menentukan profil metabolit fraksi $n$-heksana daun Semanggi menggunakan UPLC-QToF-MS/MS, dan memprediksi aktivitas neuroprotektif senyawa hasil metabolite profiling dengan studi in silico menggunakan perangkat lunak PyRX 0.8. Sejumlah $100 \mathrm{ppm}$ fraksi $n$-heksana daun Semanggi dalam DCM dan metanol disuntikkan masing-masing $5 \mu 1$ ke dalam UPLC-QToF-MS/MS, dan kemudian dianalisis dengan perangkat lunak Masslynx 4.1 untuk menentukan jenis senyawa yang terkandung. Senyawa hasil metabolite profiling kemudian di preparasi dan di seleksi menggunakan webtool SwissADME dan perangkat lunak Avogadro 1.90.0, sedangkan molecular docking dilakukan menggunakan Autodock Vina dan Biovia Discovery Studio Visualizer 2016 terhadap protein 3OLS. Hasil metabolite profiling menunjukkan sejumlah 34 predictable compounds dan 28 unknown compounds. Studi in silico menunjukkan 7 senyawa yang diprediksi memiliki aktivitas yang mirip dengan estrogen. Hasil tersebut menunjukkan bahwa fraksi $n$-heksana daun Semanggi berpotensi sebagai agen neuroprotektif sebagai terapi bagi wanita pascamenopause yang mengalami defisiensi estrogen.

Kata kunci: Marsilea crenata Presl., fitoestrogen, metabolite profiling, in silico, neuroprotektif 


\section{Pendahuluan}

Pascamenopause merupakan tahapan biologis yang terjadi sebagai bagian dari proses penuaan pada wanita dan berdampak pada terjadinya defisiensi estrogen [1]. Perempuan pascamenopause seringkali mengalami berbagai masalah kesehatan akibat defisiensi estrogen, salah satunya adalah penurunan fungsi kognitif akibat neurodegeneratif $[2,3]$.

Fitoestrogen merupakan sumber pengobatan alternatif untuk defisiensi estrogen. Fitoestrogen dapat menggantikan fungsi estrogen didalam tubuh baik dalam ikatannya dengan reseptor estrogen (ER-dependent) maupun tidak (ERindependent), sehingga merupakan alternatif pengobatan bagi neuroodegeneratif pada wanita pascamenopause yang potensial [4-6].

Semanggi (Marsilea crenata Presl.) yang terkenal di Surabaya Jawa Timur sebagai makanan khas diketahui memiliki kandungan fitoestrogen. Aktivitas ekstrak etanol 96\% dan fraksi $n$-heksana daun Semanggi akibat kandungan fitoestrogen didalamnya telah dibuktikan dari berbagai penelitian [7-12]. Meskipun memiliki potensi besar sebagai tanaman obat, kandungan senyawa dalam daun Semanggi belum sepenuhnya diketahui.

Penelitian ini dilakukan untuk mengidentifikasi profil metabolit dari fraksi $n$-heksana daun Semanggi menggunakan metode metabolite profiling dengan ultra performance liquid chromatography - quadropole time of flight - mass spectrometry (UPLC-QToF-MS/MS), dan memprediksi aktivitas neuroprotektif dari senyawa yang terkandung secara in silico terhadap reseptor estrogen- $\beta$ (ER $\beta$ ). ER $\beta$ digunakan sebagai objek molecular docking karena efek neuroprotektif yang diamati adalah melalui mekanisme antineuroinflamasi, dimana sel mikroglia yang bertanggungjawab terhadap proses tersebut regulasinya sangat dipengaruhi oleh ikatan antara estrogen dan ER $\beta[13,14]$.

UPLC-QToF-MS/MS merupakan teknik yang sangat baik dalam identifikasi profil metabolit dengan resolusi kromatografi yang tinggi, lebih cepat, lebih sensitif, menghemat waktu, dan juga lebih hemat pelarut [15]. Sedangkan melalui pendekatan in silico, prediksi sederhana terkait aktivitas senyawa dapat dibuat dengan mengkorelasikan struktur dan sifat fisikokimia menggunakan analisis perangkat lunak terhadap reseptor yang dituju $[16,17]$.

Penelitian Semanggi secara berkelanjutan bermanfaat dalam dunia kefarmasian terutama pengembangan fitofarmaka neuroprotektif, juga bermanfaat dalam upaya pelestarian kekayaan etno-cultural masyarakat Surabaya, dimana saat ini Semanggi sangat jarang ditemukan.

\section{Bahan dan Metode Penelitian}

\subsection{Bahan}

\section{Bahan Tanaman}

Daun Semanggi didapatkan dari daerah Benowo, Surabaya, Indonesia pada Mei 2019, dan kemudian diidentifikasi di UPT Materia Medika, Batu, Indonesia pada Juni 2019 dengan nomor spesimen 1a-17b-18a-1. Daun Semanggi dipreparasi sehingga didapatkan serbuk daun berwarna hijau.

\section{Bahan Kimia}

Pelarut etanol 96\% (Merck), $n$-heksana (Merck), acetonitril (Merck), asam formiat (Merck), asam sulfat (Merck), dan plat HPTLC silika gel 60 F254 (CAMAG).

\subsection{Metode}

\section{Ekstraksi dan fraksinasi}

Serbuk daun Semanggi ditimbang sebanyak 440 g lalu dicampur dengan etanol $96 \%$ dalam erlenmeyer, untuk kemudian diekstraksi metode ultrasonik assisted extraction (UAE). Ekstrak etanol 96\% daun Semanggi kemudian disuspensikan dengan aquadestilata dengan perbandingan 1:1. Suspensi kemudian di fraksinasi dengan pelarut $n$-heksana metode ekstraksi cair-cair menggunakan corong pisah. Fase $n$ heksana kemudian dipisahkan dan diuapkan menggunakan rotary evaporator Heidolph Hei-VAP ML/G3 untuk mendapatkan fraksi $n$-heksana.

\section{Metabolite profiling}

Proses identifikasi senyawa dilakukan di Laboratorium Forensik Pusat Badan Reserse Kriminal Kepolisian Negara Republik Indonesia. Fraksi $n$-heksana daun Semanggi 100 ppm sebanyak $5 \mu$ disuntikan kedalam ACQUITY UPLC® H-Class System (Waters, USA) dengan detektor MS Xevo G2-S QToF (Waters, USA). Sampel dipisahkan pada kolom ACQUITY BEH C18 $(1.7 \mu \mathrm{m} 2.1 \times 50 \mathrm{~mm})$ dengan fase gerak asetonitril $+0,05 \%$ asam formiat dan air $+0,05 \%$ asam, dengan flowrate $0,2 \mathrm{ml} /$ menit. Hasil analisis UPLC-QToFMS/MS diproses menggunakan software Masslynx Versi 4.1 untuk mendapatkan data kromatogram dan spektrum m/z dari setiap peak yang terdeteksi. Senyawa yang terdeteksi, kemudian di cek pada ChemSpider database.

\section{Molecular docking}

Struktur reseptor ER $\beta$ yang digunakan dalam penelitian ini diperoleh dari Protein Data Bank (http://www.rcsb.org) dengan kode 3OLS [16]. Persiapan awal dilakukan untuk memisahkan ligan internal (17ß-estradiol) dari protein 3OLS menggunakan Biovia Discovery Studio Visualizer 2016. 
Senyawa hasil metabolite profiling fraksi $n$-heksana daun Semanggi dipreparasi dengan Alat Web SwissADME untuk memprediksi sifat fisikokimia [18]. Senyawa tersebut kemudian di seleksi dengan menggunakan metode BOILEDEgg, apabila memenuhi kriteria dapat menembus blood brain barrier (BBB) maka akan digunakan sebagai senyawa uji molecular docking [19]. Ligan internal dan senyawa uji kemudian disiapkan dengan Avogrado 1.90.0 untuk optimasi energi. Molecular docking dilakukan menggunakan Pyrx 0.8 dengan Autodock Vina untuk simulasi proses docking [20]. Visualisasi kompleks reseptor-ligan diamati menggunakan Biovia Discovery Studio Visualizer 2016.

\section{Hasil dan Pembahasan}

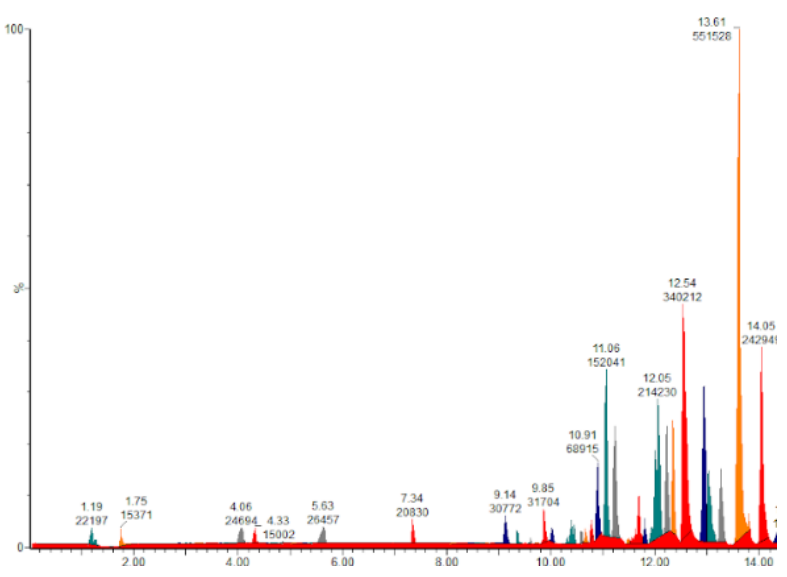

A

\subsection{Metabolite profiling}

Sejumlah 70 g ekstrak etanol $96 \%$ daun Semanggi didapatkan dari proses ekstraksi dengan metode UAE. Ekstrak ini kemudian di fraksinasi lebih lanjut untuk mendapatkan fraksi $n$-heksana sebanyak $11,9032 \mathrm{~g}$. Fraksi $n$-heksana dipilih karena pada penelitian sebelumnya, fraksi $n$-heksana diketahui memiliki khasiat dikarenakan adanya kandungan fitoestrogennya [11,12]. Hasil metabolite profiling fraksi $n$ heksana daun Semanggi dengan UPLC-QToF-MS/MS pada pelarut metanol dan DCM yang berupa total ion chromatogram (TIC) dapat dilihat pada Gambar 1, sedangkan nilai retention time $(\mathrm{Rt}), \%$ area, $\mathrm{m} / \mathrm{z}$, rumus molekul, dan nama senyawa dapat dilihat pada Tabel 1 dan Tabel 2.

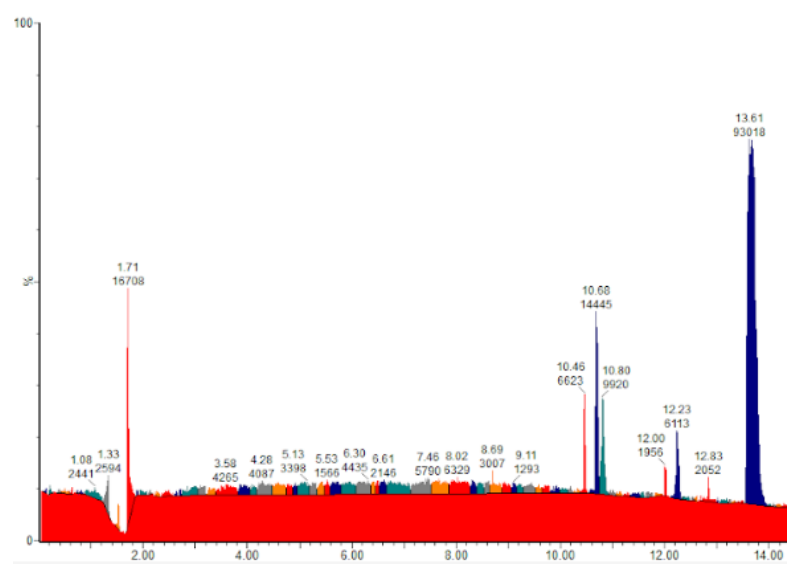

B

Gambar 1. Total ion chromatogram (TIC) fraksi $n$-heksana daun semanggi pada pelarut: (A) Metanol, dan (B) DCM.

Tabel 1

Prediksi senyawa yang terkandung dalam fraksi $n$-heksana daun semanggi dengan pelarut metanol

\begin{tabular}{|c|c|c|c|c|c|}
\hline No & $\begin{array}{c}\text { Rt } \\
\text { (menit) }\end{array}$ & $\%$ Area & $\mathbf{m} / \mathbf{z}$ & Rumus Molekul & Nama Senyawa \\
\hline 1 & 1.192 & 0.6870 & 103.0992 & $\mathrm{C}_{5} \mathrm{H}_{13} \mathrm{NO}$ & Valinol \\
\hline 2 & 1.571 & 0.0054 & 235.1423 & $\mathrm{C}_{10} \mathrm{H}_{21} \mathrm{NO}_{5}$ & $\begin{array}{l}{[(\{[1-(5-M e t h y l-1,3-o x a z o l i d i n-3-y l)-2-} \\
\text { propanyl]oxy }\} \text { methoxy)methoxy]methanol }\end{array}$ \\
\hline 3 & 2.150 & 0.0083 & 191.1915 & Unknown & Unknown \\
\hline 4 & 1.750 & 0.7642 & 302.1247 & $\mathrm{C}_{15} \mathrm{H}_{27} \mathrm{OBr}$ & 3-[(Z)-2-Bromovinyl]-2-tridecanone \\
\hline 5 & 4.332 & 0.4643 & 286.1336 & $\mathrm{C}_{15} \mathrm{H}_{23} \mathrm{O}_{3} \mathrm{Cl}$ & $\begin{array}{l}\text { 6-Chloro-9,10-dimethyl-12- } \\
\text { oxatricyclo[5.3.2.01,6]dodec-4-yl acetate }\end{array}$ \\
\hline 6 & 4.869 & 0.0287 & 268.1206 & $\mathrm{C}_{8} \mathrm{H}_{20} \mathrm{~N}_{4} \mathrm{O}_{4} \mathrm{~S}$ & $\begin{array}{c}\text { 1-[2-(Carbamimidoylammonio)ethyl]piperidinium } \\
\text { sulfate }\end{array}$ \\
\hline 7 & 5.628 & 0.8188 & 196.1100 & $\mathrm{C}_{11} \mathrm{H}_{16} \mathrm{O}_{3}$ & 2-Methyl-2-(3-oxobutyl)-1,3-cyclohexanedione \\
\hline 8 & 7.344 & 0.6447 & 264.0880 & $\mathrm{C}_{10} \mathrm{H}_{17} \mathrm{~N}_{2} \mathrm{O}_{4} \mathrm{Cl}$ & $\mathrm{N}$-(Chloroacetyl)leucylglycine \\
\hline 9 & 9.135 & 0.9524 & 180.1127 & $\mathrm{C}_{7} \mathrm{H}_{12} \mathrm{~N}_{6}$ & 5-(2-Cyclohexylidenehydrazino)-2H-tetrazole \\
\hline 10 & 9.347 & 0.2919 & 827.4181 & $\mathrm{C}_{39} \mathrm{H}_{57} \mathrm{~N}_{9} \mathrm{O}_{11}$ & $\begin{array}{l}\text { (2S,11E,15S,18S,21S,24S)-15-(2-Amino-2- } \\
\text { oxoethyl)-2-benzyl-24-carbamoyl-18-cyclohexyl-21- } \\
\text { isopropyl-25-methyl-4,7,10,13,16,19,22-heptaoxo- } \\
3,6,9,14,17,20,23 \text {-heptaazahexacos-11-en-1-oic acid }\end{array}$ \\
\hline
\end{tabular}




\begin{tabular}{lllll}
\hline 11 & 9.610 & 0.0841 & 552.2933 & $\mathrm{C}_{29} \mathrm{H}_{44} \mathrm{O}_{10}$
\end{tabular}

\begin{tabular}{ccccc}
\hline 12 & 9.852 & 0.9812 & 670.3174 & $\mathrm{C}_{29} \mathrm{H}_{46} \mathrm{~N}_{6} \mathrm{O}_{12}$ \\
& & & & \\
\hline 13 & 10.010 & 0.3244 & 489.2860 & $\mathrm{C}_{12} \mathrm{H}_{31} \mathrm{~N}_{19} \mathrm{O}_{3}$ \\
\hline 14 & 10.389 & 1.0747 & 285.1365 & $\mathrm{C}_{17} \mathrm{H}_{19} \mathrm{NO}_{3}$ \\
\hline 15 & 10.568 & 0.2946 & 595.3035 & $\mathrm{C}_{28} \mathrm{H}_{45} \mathrm{~N}_{5} \mathrm{O}_{7} \mathrm{~S}$
\end{tabular}

\begin{tabular}{ccccc}
\hline 16 & 10.663 & 0.3210 & 508.2675 & $\mathrm{C}_{27} \mathrm{H}_{40} \mathrm{O}_{9}$ \\
\hline 17 & 10.78 & 0.4605 & 467.3263 & $\mathrm{C}_{27} \mathrm{H}_{41} \mathrm{~N}_{5} \mathrm{O}_{2}$ \\
& & & & \\
\hline 18 & 10.905 & 2.1329 & 503.3061 & $\mathrm{C}_{3} \mathrm{H}_{29} \mathrm{~N}_{29} \mathrm{O}_{2}$ \\
\hline 19 & 11.063 & 4.7056 & 693.3891 & $\mathrm{C}_{41} \mathrm{H}_{51} \mathrm{~N}_{5} \mathrm{O}_{5}$
\end{tabular}

\begin{tabular}{llllll}
\hline 20 & 11.222 & 3.7288 & 517.3152 & $\mathrm{C}_{28} \mathrm{H}_{43} \mathrm{~N}_{3} \mathrm{O}_{6}$ & $\begin{array}{c}\mathrm{N}-[(\text { trans-4- }\{[(\mathrm{N}-\{[(2-\mathrm{Methyl}-2 \\
\text { propanyl)oxy }] \text { carbonyl }\}-\mathrm{L}-\end{array}$
\end{tabular}

(1R,2S,3R,4aR,5S,6R,8S,8aR)-8-Acetoxy-8a(acetoxymethyl)-5-[(2S,3aR,6aS)-

hexahydrofuro[2,3-b]furan-2-yl]-3-hydroxy-5,6dimethyloctahydro-2H-spiro[naphthalene-1,2'oxiran]-2-yl (2S)-2-methylbutanoate

N-Acetyl-L- $\alpha$-aspartyl-L- $\alpha$-aspartyl-L-isoleucyl-L-

valyl-L-prolyl-L-alanine Uydromorphone

(2R)-N1-[(2S)-3-Cyclohexyl-1-( \{ [(4-

morpholinylsulfonyl)amino]methyl \}amino)-1-oxo-2propanyl]-N4-hydroxy-2-[3-(4-

methylphenyl)propyl]succinamide Ajugamarin E2

N-[3-(Diethylamino)propyl]-N'-[4-methyl-2-(4methyl-1-piperidinyl)-6-quinolinyl]succinamide

\begin{tabular}{llllll}
\hline 19 & 11.063 & 4.7056 & 693.3891 & $\mathrm{C}_{41} \mathrm{H}_{51} \mathrm{~N}_{5} \mathrm{O}_{5}$ & $\begin{array}{r}\mathrm{N}-[(2 \mathrm{~S})-1-\{[(2 \mathrm{~S}, 3 \mathrm{R})-3-\mathrm{Hydroxy}-4-\{(2 \mathrm{~S}, 4 \mathrm{R})-2-[(2- \\
\text { methyl-2-propanyl)carbamoyl }-4-\text { phenoxy-1- }\end{array}$
\end{tabular}
piperidinyl\}-1-phenyl-2-butanyl]amino $\}-3-$ methyl-1oxo-2-butanyl]-2-

alloisoleucyl)amino]methyl\}cyclohexyl)carbonyl]-Lphenylalanine

\begin{tabular}{ccccc}
\hline 21 & 11.496 & 0.1386 & 508.2781 & $\mathrm{C}_{26} \mathrm{H}_{40} \mathrm{~N}_{2} \mathrm{O}_{8}$ \\
\hline 22 & 11.696 & 1.9931 & 573.3256 & $\mathrm{C}_{17} \mathrm{H}_{39} \mathrm{~N}_{19} \mathrm{O}_{2} \mathrm{~S}$ \\
\hline 23 & 11.801 & 0.6565 & 495.3602 & $\mathrm{C}_{18} \mathrm{H}_{45} \mathrm{~N}_{11} \mathrm{O}_{5}$ \\
\hline 24 & 12.054 & 6.6303 & 495.3583 & $\mathrm{C}_{14} \mathrm{H}_{41} \mathrm{~N}_{17} \mathrm{O}_{3}$ \\
\hline 25 & 12.233 & 3.1292 & 531.3408 & $\mathrm{C}_{27} \mathrm{H}_{49} \mathrm{NO}_{9}$
\end{tabular}

Dibutyl 4,19-dioxo-5,18-dioxa-3,20-diazadocosa10,12-diyne-1,22-dioate

Unknown

(3R,4S,6S,9R,11R,12R,13S,14R)-6-

$\{[(2 S, 3 R, 4 S, 6 S)-4-($ Dimethylamino)-3-hydroxy-6methyltetrahydro-2H-pyran-2-yl]oxy $\}$-14-ethyl4,12,13-trihydroxy-3,9,11,13-

tetramethyloxacyclotetradecane-2,10-dione

\begin{tabular}{cccccc}
\hline 26 & 12.338 & 3.3329 & 671.4105 & $\mathrm{C}_{32} \mathrm{H}_{57} \mathrm{~N}_{5} \mathrm{O}_{10}$ & Unknown \\
\hline 27 & 12.538 & 10.5293 & 495.3336 & $\mathrm{C}_{5} \mathrm{H}_{37} \mathrm{~N}_{25} \mathrm{OS}$ & $\begin{array}{c}\text { 2-Oxo-2-(1-piperazinyl)-N-(2- } \\
\text { sulfamoylethyl)acetamide }\end{array}$ \\
\hline 28 & 12.950 & 5.1347 & 497.3729 & $\mathrm{C}_{29} \mathrm{H}_{47} \mathrm{~N}_{5} \mathrm{O}_{2}$ & $\begin{array}{c}\text { 1-(Diethylamino)-3-(4-\{6-[(6-methoxy-4-methyl-8- } \\
\text { quinolinyl)amino]hexyl\}-1-piperazinyl)-2-propanol } \\
\text { hydrochloride }\end{array}$ \\
\hline 30 & 13.034 & 3.0219 & 521.3493 & $\mathrm{C}_{28} \mathrm{H}_{48} \mathrm{~N}_{5} \mathrm{O}_{2} \mathrm{Cl}$ & $\begin{array}{c}\text { acetic acid;2-[bis(2-hydroxyethyl)amino]ethyl (E)- } \\
\text { octadec-9-enoate }\end{array}$ \\
\hline 31 & 13.613 & 17.0694 & 473.3728 & $\mathrm{C}_{27} \mathrm{H}_{47} \mathrm{~N}_{5} \mathrm{O}_{2}$ & $\begin{array}{c}\text { (4S)-4-\{[4-(Diethylamino)benzyl]amino }-\mathrm{N}-(2- \\
\text { methoxyethyl)-1-(1-propyl-4-piperidinyl)-L- } \\
\text { prolinamide }\end{array}$ \\
\hline 32 & 14.045 & 7.5191 & 499.3872 & $\mathrm{C}_{28} \mathrm{H}_{53} \mathrm{NO}_{6}$ & $\begin{array}{c}\text { Ethyl (3R)-3-(6-methoxy-2,2- } \\
\text { dimethyltetrahydrofuro[2,3-d][1,3]dioxol-5-yl)-3- } \\
\text { (pentadecylamino)propanoate }\end{array}$ \\
\hline 33 & 14.329 & 0.4782 & 523.3642 & $\mathrm{C}_{14} \mathrm{H}_{41} \mathrm{~N}_{19} \mathrm{O}_{3}$ & Unknown \\
\hline 34 & 14.562 & 0.5406 & 341.3278 & $\mathrm{Unknown}_{2}$ & Unknown \\
\hline 35 & 14.899 & 0.3358 & 304.2408 & $\mathrm{C}_{20} \mathrm{H}_{32} \mathrm{O}_{2}$ & Methandriol \\
\hline 36 & 15.225 & 0.0889 & 698.5868 & $\mathrm{C}_{46} \mathrm{H}_{74} \mathrm{~N}_{4} \mathrm{O}_{2}$ & Unknown \\
\hline & 15.299 & 0.0221 & 698.5876 & $\mathrm{C}_{34} \mathrm{H}_{78} \mathrm{~N}_{6} \mathrm{O}_{8}$ & Unknown \\
\hline
\end{tabular}




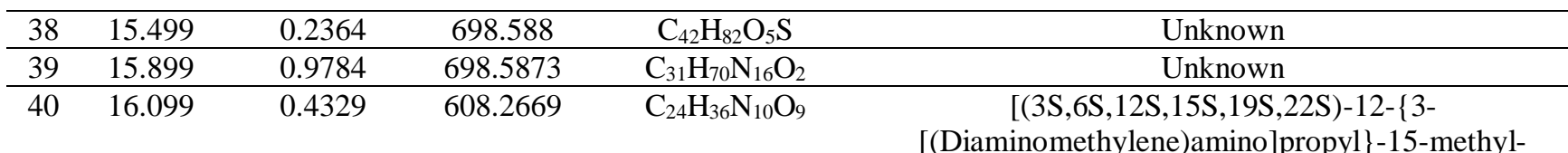

$5,8,11,14,17,21,23$-heptaoxo-1,4,7,10,13,16,20-

heptaazatricyclo[17.3.1.13,22]tetracos-6-yl]acetic acid

\begin{tabular}{cccccc}
\hline 41 & 16.278 & 0.1085 & 698.5894 & $\mathrm{C}_{43} \mathrm{H}_{78} \mathrm{~N}_{4} \mathrm{OS}$ & Unknown \\
\hline 42 & 16.532 & 0.8647 & 608.2615 & $\mathrm{C}_{39} \mathrm{H}_{36} \mathrm{~N}_{4} \mathrm{OS}$ & $\begin{array}{c}\text { N-(1-\{5-[(3-Methylbenzyl)sulfanyl]-4-(4- } \\
\text { methylphenyl)-4H-1,2,4-triazol-3-yl\}-2- } \\
\text { phenylethyl)-2,2-diphenylacetamide }\end{array}$ \\
\hline 43 & 16.953 & 7.8715 & 592.2667 & $\mathrm{C}_{18} \mathrm{H}_{40} \mathrm{~N}_{8} \mathrm{O}_{14}$ & Unknown \\
\hline 44 & 17.09 & 0.8036 & $\begin{array}{c}1087.627 \\
8\end{array}$ & $\mathrm{C}_{52} \mathrm{H}_{85} \mathrm{~N}_{11} \mathrm{O}_{14}$ & $\begin{array}{c}\text { L-Phenylalanyl-L-leucyl-L-lysyl-L- } \alpha \text {-glutamyl-L- } \\
\text { prolyl-L-valyl-L-lysyl-L- } \alpha \text {-glutamyl-L-valine }\end{array}$ \\
\hline 45 & 17.227 & 0.2080 & 698.5887 & $\mathrm{C}_{42} \mathrm{H}_{82} \mathrm{O}_{5} \mathrm{~S}$ & Unknown \\
\hline 46 & 17.374 & 2.5841 & 592.2709 & $\mathrm{C}_{23} \mathrm{H}_{40} \mathrm{~N}_{6} \mathrm{O}_{12}$ & $\begin{array}{c}\text { L-Threonyl-L-threonyl-L-leucyl-L-seryl-L- } \alpha- \\
\text { aspartylglycine }\end{array}$ \\
\hline 47 & 17.69 & 0.0186 & 698.5911 & $\mathrm{C}_{36} \mathrm{H}_{70} \mathrm{~N}_{14}$ & Unknown \\
\hline 48 & 17.827 & 3.5815 & 925.5775 & $\mathrm{C}_{50} \mathrm{H}_{79} \mathrm{~N}_{5} \mathrm{O}_{11}$ & Unknown \\
\hline 49 & 18.344 & 0.4206 & 1115.662 & $\mathrm{C}_{49} \mathrm{H}_{81} \mathrm{~N}_{25} \mathrm{O}_{4} \mathrm{~S}$ & Unknown \\
\hline 50 & 20.419 & 0.1283 & 191.155 & Unknown & Unknown \\
\hline
\end{tabular}

Tabel 2

Prediksi senyawa yang terkandung dalam fraksi $n$-heksana daun semanggi dengan pelarut DCM

\begin{tabular}{|c|c|c|c|c|c|}
\hline No & $\begin{array}{c}\mathbf{R t} \\
\text { (menit) }\end{array}$ & $\%$ Area & $\mathbf{m} / \mathbf{z}$ & Rumus Molekul & Nama Senyawa \\
\hline 1 & 1.078 & 0.2747 & 191.1621 & Unknown & Unknown \\
\hline 2 & 1.508 & 0.1622 & 123.0915 & Unknown & Unknown \\
\hline 3 & 8.693 & 0.3384 & 274.1654 & $\mathrm{C}_{13} \mathrm{H}_{24} \mathrm{NO}_{5}$ & $\begin{array}{l}\text { 4-Methyl 3-(2-methyl-2-propanyl) (4R,5R)-2,2,5- } \\
\text { trimethyl-1,3-oxazolidine-3,4-dicarboxylate }\end{array}$ \\
\hline 4 & 10.684 & 2.3712 & 287.2824 & $\mathrm{C}_{17} \mathrm{H}_{37} \mathrm{NO}_{2}$ & 2,2'-(Tridecylimino)diethanol \\
\hline 5 & 10.801 & 1.1165 & 241.2773 & $\mathrm{C}_{16} \mathrm{H}_{35} \mathrm{~N}$ & Dioctylamine \\
\hline 6 & 12.001 & 0.2202 & 315.3144 & Unknown & Unknown \\
\hline 7 & 12.233 & 0.6880 & 315.3133 & $\mathrm{C}_{19} \mathrm{H}_{41} \mathrm{NO}_{2}$ & 2-Amino-3-(hexadecyloxy)-1-propanol \\
\hline 8 & 12.833 & 0.2309 & 436.254 & $\mathrm{C}_{19} \mathrm{H}_{40} \mathrm{~N}_{4} \mathrm{O}_{3} \mathrm{~S}_{2}$ & Unknown \\
\hline 9 & 15.815 & 9.0406 & 387.3343 & $\mathrm{C}_{22} \mathrm{H}_{43} \mathrm{NO}$ & Erucamide \\
\hline 10 & 16.532 & 20.7510 & 735.6029 & $\mathrm{C}_{45} \mathrm{H}_{77} \mathrm{~N}_{5} \mathrm{O}_{3}$ & Unknown \\
\hline 11 & 17.290 & 64.7549 & 1097.7563 & $\mathrm{C}_{56} \mathrm{H}_{103} \mathrm{~N}_{7} \mathrm{O}_{14}$ & Unknown \\
\hline 12 & 22.347 & 0.0512 & 191.1554 & Unknown & Unknown \\
\hline
\end{tabular}

Hasil metabolite profiling menunjukkan total 34 predictable compounds dan 28 unknown compounds, baik pada pelarut metanol maupun DCM. Penggunaan kedua pelarut ini bertujuan untuk mengelusi fraksi $n$-heksana secara optimal pada kolom UPLC-QToF-MS/MS. Tidak semua peak pada TIC yang dapat diidentifikasi pada proses metabolite profiling, hal ini dapat terlihat dengan adanya unknown compounds sejumlah 28 buah. Unknown compounds merupakan senyawa yang tidak dapat teridentifikasi oleh database, dapat berupa senyawa pengotor atau degradan yang masih terdeteksi oleh instrumen, atau mungkin senyawa baru yang belum ada dalam database, terutama unknown compounds yang memiliki kadar tinggi [21].

\subsection{Molecular docking}

Molecular docking menjadi pendekatan populer untuk memprediksi aktivitas suatu senyawa dengan biaya murah serta waktu yang relatif cepat [18]. Prediksi aktivitas neuroprotektif diawali dengan melakukan skrining awal terhadap senyawa hasil metabolite profiling fraksi $n$-heksana daun Semanggi. Syarat yang harus dimiliki oleh senyawa untuk memiliki efek neuroprotektif adalah mampu melewati BBB [22], sehingga skrining awal perlu dilakukan dengan pengamatan nilai topological polar surface area (TPSA) tiap senyawa, dimana senyawa yang memiliki nilai TPSA $<70 \AA^{2}$ akan mampu menembus dan berefek pada BBB $[23,24]$. Salah 
satu metode skrining tersebut dapat dilakukan menggunakan open source webtool SwissADME [23] (Gambar 2).

Senyawa yang telah melewati tahapan skrining serta memiliki nilai TPSA $<70 \AA^{2}$ dilanjutkan dengan optimasi geometri struktur untuk menemukan struktur paling stabil, yaitu dengan metode MMFF 94 dalam aplikasi Avogadro
[24]. Molecular docking kemudian dilakukan terhadap senyawa yang lolos seleksi menggunakan program PyRx 0.8 dan AutoDock Vina sebagai docking simulator. Dari hasil analisis dengan Biovia Discovery Studio Visualizer 2016, ditemukan bahwa ada 7 senyawa yang diprediksi sebagai agonis ER $\beta$, seperti yang tercantum dalam Tabel 3 [25,26].

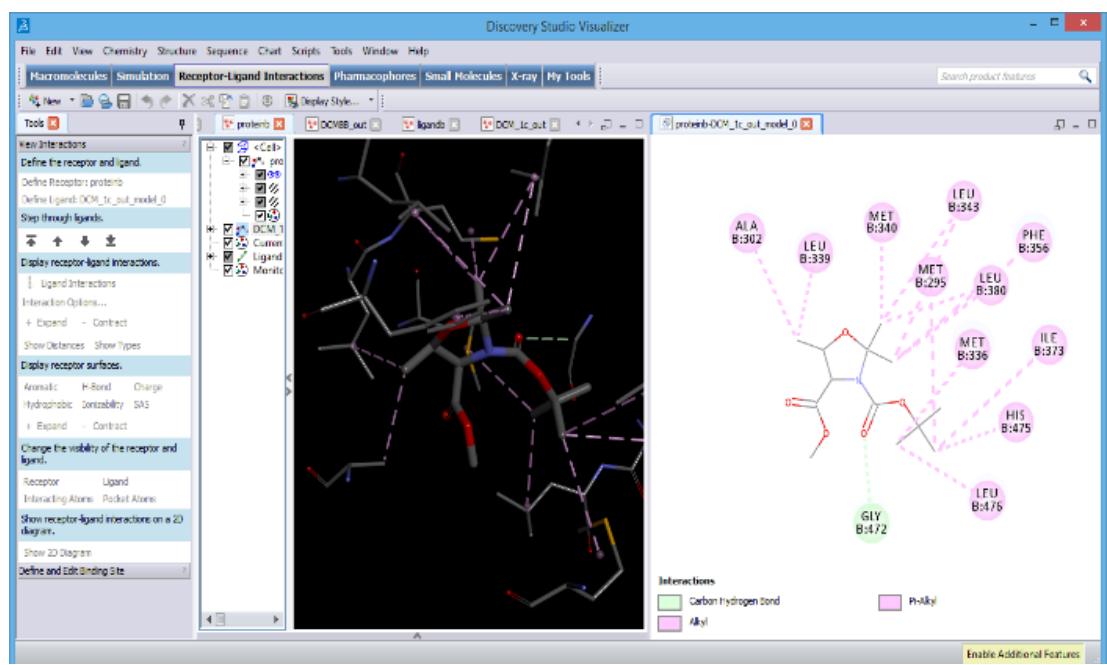

Gambar 2. Analisis salah satu senyawa fraksi $n$-heksana daun Semanggi menggunakan Biovia Discovery Studio Visualizer 2016.

Tabel 3

Senyawa dalam fraksi $n$-heksana daun semanggi yang agonis terhadap $17 \beta$-estradiol

\begin{tabular}{|c|c|c|c|c|c|}
\hline No. & $\begin{array}{c}\text { Kodifikasi } \\
\text { Senyawa }\end{array}$ & Nama Senyawa & $\begin{array}{l}\text { Binding } \\
\text { Affinity }\end{array}$ & TPSA & Asam Amino \\
\hline 1 & MTL 12 & Hydromorphone & -8.8 & 49,77 & $\begin{array}{l}\text { His } 475 \text {; } \\
\text { Glu } 305\end{array}$ \\
\hline 2 & MTL 15 & $\begin{array}{l}\mathrm{N} \text {-[3-(Diethylamino)propyl]-N'-[4- } \\
\text { methyl-2-(4-methyl-1-piperidinyl)-6- } \\
\text { quinolinyl]succinamide }\end{array}$ & -0.7 & 62,75 & $\begin{array}{l}\text { His } 475 \text {; } \\
\text { Glu } 305\end{array}$ \\
\hline 3 & MTL 20 & $\begin{array}{c}\text { 2-Ethyl-N- }\{[5 \text {-(4-ethyl-1-piperazinyl)-3- } \\
\text { methyl-1-phenyl-1H-pyrazol-4- } \\
\text { yl]methyl }\}-\mathrm{N}-(3- \\
\text { methoxypropyl)hexanamide }\end{array}$ & 7.5 & 53,84 & $\begin{array}{l}\text { His } 475 \text {; } \\
\text { Arg } 346\end{array}$ \\
\hline 4 & MTL 25 & 17a-Methyl-5-androstene-3B,17B-diol. & -5.9 & 40,46 & $\begin{array}{l}\text { His } 475 \text {; } \\
\text { Glu } 305\end{array}$ \\
\hline 5 & DCM 2 & 2,2'-(Tridecylimino)diethanol & -6.0 & 43,70 & $\begin{array}{l}\text { His } 475 \text {; } \\
\text { Glu } 305\end{array}$ \\
\hline 6 & DCM 3 & Dioctylamine & -5.6 & 12,03 & $\begin{array}{c}\text { His 475; Glu 305; } \\
\text { Arg } 346\end{array}$ \\
\hline 7 & DCM 4 & 2-Amino-3-(hexadecyloxy)-1-propanol & -5.8 & 55,48 & $\begin{array}{c}\text { His 475; Glu 305; } \\
\text { Arg } 346\end{array}$ \\
\hline Kontrol & - & $17 \beta$-estradiol & $-10,5$ & - & $\begin{array}{c}\text { His } 475 \text {; Glu } 305 \text {; } \\
\text { Arg } 346\end{array}$ \\
\hline
\end{tabular}

ER $\beta$ hadir dalam beberapa jenis sel di otak, salah satunya adalah sel mikroglia. Sel mikroglia bertanggung jawab atas proses neuroinflamasi yang merupakan salah satu penyebab utama neurodegeneratif. Dalam neuroinflamasi, penurunan jumlah ikatan estrogen dan ER $\beta$ memicu peningkatan jumlah sel mikroglia yang teraktivasi dalam jalur M1 polarity, dan 
menyebabkan peningkatan sitokin inflamasi seperti interleukin-1 (IL-1), interleukin-6 (IL-6), tumor necrosis factor- $\alpha$ (TNF- $\alpha)$, dan nitric oxide (NO) di otak. Kejadian ini akan mengurangi fungsi sinaptik dan plastisitas neuron, sehingga memicu terjadinya neurodegeneratif [14]. Oleh karena itu, penambahan fitoestrogen sebagai substituen estrogen akan memiliki efek neuroprotektif, dengan merubah aktivasi sel mikroglia dari M1 polarity yang bersifat proinflamasi menjadi M2 polarity yang bersifat antiinflamasi [27].

Senyawa dikatakan sebagai golongan fitoestrogen atau agonis estrogen (17 $\beta$-estradiol) apabila senyawa tersebut berikatan dengan minimal dua asam amino His 475 dan Glu 305 dari tiga asam amino yang diikat oleh gugus farmakofor $17 \beta$-estradiol pada ER $\beta$. Nilai binding affinity juga menunjukkan kestabilan senyawa dalam berikatan dengan ER $\beta$, semakin kecil nilai binding affinity, maka semakin stabil senyawa tersebut [26]. Dari Tabel 3, diketahui senyawa yang termasuk dalam fitoestrogen dari fraksi $n$-heksana daun Semanggi antara lain : 2,2'-(Tridecylimino) diethanol; Dioctylamine; 2-Amino-3-(hexadecyloxy)-1-propanol; Hydromorphone; N-[3-(Diethylamino)propyl]-N'-[4-methyl2-(4-methyl-1-piperidinyl)-6-quinolinyl] succinamide; 2 Ethyl-N-\{[5-(4-ethyl-1-piperazinyl)-3-methyl-1-phenyl-1Hpyrazol-4-yl]methyl\}-N-(3-methoxypropyl)hexanamide; 17aMethyl-5-androstene-3B,17B-diol.

\section{Kesimpulan}

Proses metabolite profiling menunjukkan sejumlah 34 predictable compounds dan 28 unknown compounds, sedangkan studi in silico menunjukkan 7 senyawa yang diprediksi memiliki aktivitas yang mirip dengan estrogen. Hasil tersebut menunjukkan bahwa fraksi $n$-heksana daun Semanggi berpotensi sebagai agen neuroprotektif sebagai terapi bagi wanita pascamenopause yang mengalami defisiensi estrogen.

\section{Penghargaan}

Penelitian ini didanai oleh Bantuan Operasional Perguruan Tinggi Negeri (BOPTN) Universitas Islam Negeri Maulana Malik Ibrahim Malang.

\section{Daftar Pustaka}

[1] Lee WL, Tsui KH, Seow KM, Cheng MH, Su WH, Chen CP, Wang PH. 2013. Hormone Therapy for Postmenopausal Women-An Unanswered Issue. Gynecology and Minimally Invasive Therapy. 2(1): 13-17.

[2] Klempin F, dan Kempermann G. 2007. Adult Hippocampal Neurogenesis and Aging. European Archives of Psychiatry and Clinical Neuroscience. 257(5): 271-280.

[3] Dipiro JT, Robert LT, Gary CY. 2008. Pharmacotherapy (A Pathophysiologic Approach), 7th Edition. United States: McGraw-Hill Companies Inc.
[4] Villiers T. 2009. Bone Health and Osteoporosis in Postmenopausal Women. Best Practice and Research: Clinical Obstetrics and Gynaecology. 23(1): 73-85.

[5] Yang TS, Wang SY, Yang YC, Su CH, Lee FK, Chen SC, Tseng CY, Jou HJ, Huang JP, Huang KE. 2012. Effects of Standardized Phytoestrogen on Taiwanese Menopausal Women. Taiwanese Journal of Obstetrics and Gynecology. 51(2): 229-235.

[6] Cui J, Shen Y, Li R. 2013. Estrogen Synthesis and Signaling Pathways During Aging: from Periphery to Brain. Trends in Molecular Medicine. 19(3): 197-209.

[7] Laswati H. 2011. Green Clover Potentiates Delaying the Increment of Imbalance Bone Remodeling Process in Postmenopausal Women. Folia Medica Indonesiana. 47(2): 112-117.

[8] Nurjanah, Azka A, Abdullah A. 2012. Aktivitas Antioksidan dan Komponen Bioaktif Semanggi Air (Marsilea crenata). Jurnal Inovasi dan Kewirausahaan. 1(3): 152-158.

[9] Ma'arif B, Agil M, Laswati H. 2016. Phytochemical Assessment on n-Hexane Extract and Fractions of Marsilea crenata Presl. Leaves Through GC-MS. Traditional Medicine Journal. 21(2): 77-85.

[10] Ma'arif B, Agil M, Laswati H. 2020. The Enhancement of Arg1 and Activated ER $\beta$ Expression in Microglia HMC 3 by Induction of $96 \%$ Ethanol Extract of Marsilea crenata Presl. Leaves. Journal of Basic and Clinical Physiology and Pharmacology. 30(6): 1-7.

[11] Ma'arif B, Agil M, Laswati H. 2018. Alkaline Phosphatase Activity of Marsilea crenata Presl. Extract and Fractions as Marker of MC3T3-E1 Osteoblast Cell Differentiation. Journal of Applied Pharmaceutical Science. 8(3): 55-59.

[12] Agil M, Ma'arif B, Aemi NY. 2018. Aktivitas Antiosteoporosis Fraksi $n$-Heksana Daun Marsilea crenata Presl. dalam Meningkatkan Kepadatan Tulang Trabekular Vertebra Mencit Betina. Jurnal Tumbuhan Obat Indonesia. 11(2): 1-7.

[13] Au A, Feher A, McPhee L, Jessa A, Oh S, Einstein G. 2016. Estrogens, Inflammation and Cognition. Frontiers in Neuroendocrinology. 40: 87-100.

[14] Engler-Chiurazzi EB, Brown CM, Povroznik JM, Simpkins JW. 2017. Estrogens as Neuroprotectants: Estrogenic Actions in the Context of Cognitive Aging and Brain Injury. Progress in Neurobiology. 157: 188-211.

[15] Patil VP, Tathe RD, Devdhe SJ, Angadi SS, Kale SH. 2011. Ultra Performance Liquid Chromatography: A Review. International Research Journal of Pharmacy. 2(6): 39-44.

[16] Hardjono S. 2013. Sintesis dan Uji Aktivitas Antikanker Senyawa 1-(2-Klorobenzoiloksi)urea dan 1-(4Klorobenzoiloksi)urea. Berkala Ilmiah Kimia Farmasi. 2(1): 16-21.

[17] Novikov FN, dan Chilov GG. 2009. Molecular Docking: Theoretical Background, Practical Applications and Perspectives. Mendeleev Communications. 19(5): 237-242.

[18] Muchtaridi M, Dermawan D, Yusuf M. 2018. Molecular Docking, 3D Structure-Based Pharmacophore Modeling, and ADME Prediction of Alpha Mangostin and Its Derivatives against Estrogen Receptor Alpha. Journal of Young Pharmacists. 10(3): 252-259.

[19] Sliwoski GR, Meiler J, Lowe EW. 2014. Computational Methods in Drug Discovery Prediction of Protein Structure and 
Ensembles from Limited Experimental Data View Project Antibody Modeling, Antibody Design and Antigen-Antibody Interactions View Project. Computational Methods in Drug Discovery. 66(1): 334-395.

[20] Martin YC. 2005. A Bioavailability Score. Journal of Medicinal Chemistry. 48(9): 3164-3170.

[21] Ma'arif B, Mirza DM, Suryadinata A, Muchlisin MA, Agil M. 2019. Metabolite Profiling of $96 \%$ Ethanol Extract from Marsilea crenata Presl. Leaves Using UPLC-QToF-MS/MS and Anti-Neuroinflammatory Predicition Activity with Molecular Docking. Journal of Tropical Pharmacy and Chemistry. 4(6): 261-270.

[22] Kelder J, Grootenhuis DJP, Bayada DM, Delbressine PCL, Ploemen JP. 1999. Molecular Surface as a Dominating Determinant for Oral Absorption and Brain Penetration of Drugs. Pharmaceutical Research. 16(10): 1514-1519.

[23] Daina A, Michielin O, Zoete V. 2017. SwissADME: A Free Web Tool to Evaluate Pharmacokinetics, Drug-Likeness and Medicinal Chemistry Friendliness of Small Molecules. Scientific Reports. 7: 1-13.

[24] Hanwell MD, Curtis DE, Lonie DC, Vandermeerschd T, Zurek E, Hutchison GR. 2012. Avogadro: An Advanced Semantic Chemical Editor, Visualization, and Analysis Platform. Journal of Cheminformatics. 4(1): 1-17.

[25] Trott O, dan Olson AJ. 2010. Autodock Vina: Improving the Speed and Accuracy of Docking with a New Scoring Function, Efficient Optimization and Multithreading. J Comput Chem. 31(2): 455-461.

[26] Siswandono, dan Soekardjo B. 1995. Kimia Medisinal. Surabaya: Airlangga University Press.

[27] Cui L, Zahedi P, Saraceno J, Bristow R, Jaffray D, Allen C. 2013. Neoplastic Cell Response to Tiopronin-Coated Gold Nanoparticles. Nanomedicine: Nanotechnology, Biology, and Medicine. 9(2): 264-273. 